Article received on March $9^{\text {th }} 2019$

Article accepted on May $16^{\text {th }} 2019$

UDC: 78.02

159.9:78

\title{
Blanka Bogunović*
}

University of Arts in Belgrade

Faculty of Music

\section{CREATIVE COGNITION IN COMPOSING MUSIC ${ }^{1}$}

\begin{abstract}
We present an overview of theoretical and empirical research in a domain of cognitive psychology of music, psychology of creativity and interdisciplinary studies concerning the creative cognitive processes in composing music. The wide scope of knowledge, within a time span of some 35 years, is introduced covering the following themes - generative models of creative cognition, metacognitive strategies in composing, the relation between creativity, knowledge and novelty, creativity in the social-economical context. Further on, models and concepts, new research methodologies and results that were developed specifically in a domain of music creation, will be presented. The intention is to introduce and bring into connection relevant psychological and interdisciplinary knowledge about creative cognition processes in composing contemporary art music and raising questions about further research.
\end{abstract}

Keywords: cognition, creativity, composition, creative process, creative act, creative cognition, interdisciplinarity, theoretical models of creativity, generative process

\footnotetext{
* Author contact information: bbogunovic@rcub.bg.ac.rs

1 This research was carried out as a part of the scientific projects Identities of Serbian Music in the World Cultural Context (No. 177019) and Identification, measurement and development of the cognitive and emotional competencies important for a Europe-oriented society (No. 179018), supported by the Ministry of Education, Science, and Technological Development of the Republic of Serbia (2011-2019).
} 


\section{Introduction}

Understanding a complex phenomenon such as creativity in arts, specifically music, has been a challenge for many disciplines and authors, artists and scientists. In this article, we shall take a scientific approach to creative processes in music, more concretely composing music, since improvisation is thought of as creative behaviour, as well. ${ }^{2}$ Furthermore, we bring into focus the cognitive processes in composing music since the key role of cognitive mechanisms and processes was shown in our previous research. ${ }^{3}$ The results regarding the intertwined act of emotional experience, imagery and cognitive processes on composing contemporary music within the framework of nature versus culture were published or presented earlier, ${ }^{4}$ as well as on the communication of emotional content between composers, performers and the audience. ${ }^{5} \mathrm{We}$ shall approach the theme of creative cognition from the point of view of two psychological subdisciplines, the cognitive psychology of music and the psychology of creativity, in the attempt to integrate the knowledge that comes from both sides, which could explain the role of creative cognition in composing music. We shall give an overview of scientific investigation, theoretical and empirical, present respected models of composing in the psychology of music and conceptions of cognitive processes in creativity, which could be referred to or applied in the field of music. Further on, models and concepts, new research methodologies and results, developed specifically in the domain

2 Ksenija Radoš, Psihologija muzike [Psychology of Music], Beograd, Zavod za udžbenike, 2010 ( $2^{\text {nd }}$ edition).

3 Blanka Bogunović, "Psihologija i muzika: Kognicija i afekat u stvaranju savremene umetničke muzike" ["Psychology and Music: Cognition and Affect in Creating Contemporary Art Music"], Paper presented at $24^{\text {th }}$ International Review of Composers, Belgrade, Serbian Composers' Association. Retrieved on January 25, 2019, from http://composers. rs/?page_id=4259

4 Blanka Bogunović, Tijana Popović Mladjenović, "Emotion, Cognition and Imagery", in: Tijana Popović Mladjenović, Blanka Bogunović, Ivana Perković, Interdisciplinary Approach to Music: Listening, Performing, Composing, Belgrade, Faculty of Music, 2014, 191-227.

5 Blanka Bogunović, Milica Erić, "Emocionalni doživljaj muzičkog komada: Komunikacija izmeću kompozitora, izvođača i publike" ["Emotional Experience of Musical Piece: Communication Between Composer, Performer and Audience"], in: Knjiga rezimea 22. konferencije Empirijska istraživanja u psihologiji [Abstract Book of 22. Conference on Empirical Research in Psychology], Belgrade, Institute for Psychology and Laboratory for Experimental Psychology, Faculty of Philosophy, University of Belgrade, 2016, 43-44. 
of musical creativity, will be discussed. The intention is to introduce and bring into connection the relevant psychological and interdisciplinary knowledge about creative cognition processes in composing contemporary art music.

\section{First conceptual models on composing music}

In the field of the psychology of music, research that deals with (contemporary) composing as creative and cognitive activity is rare, though interdisciplinary interest has been evolving in the last decade. Problems that slow down the progress in this field rise within the epistemological, methodological, theoretical and collaborative fields. Namely, the complexity and hidden nature of the process is hardly accessible to investigation. Sloboda reported about the methodological procedures that were usually used in order to understand processes of composing of the whole musical piece, and have their limitations, namely sketch analysis, 'live' observations of the compositional process and an examination of what composers say (interview) about their own compositional processes throughout and after a working session ${ }^{6}$. One reason more lies in the difficulties to obtain long term cooperation between composers and psychologists presumably because of the differences in 'language', methodology and the theoretical discourse of their disciplines, besides the complexity of the process itself. The first are interested in the 'large scale architecture' and the second in the microstructural fragments mainly of conventional music ${ }^{7}$. Also, it is sometimes difficult for artists to verbally express the contents of the inner processes or they are reluctant to expose them, fearing that designation will take the 'magic' away. The source of difficulties is the lack of theoretical models that would be referential for the domain of music creation and serve as a kind of framework for research. Though, there were authors that tried to bring together the knowledge of cognition and creativity and apply it in the field of music.

John Sloboda started with the psychological research of composing (as a process), stating that this part of the creative chain is neglected for the sake of a higher interest in the product of composition ${ }^{8}$. He was referring to a creative process formula made of 'four P's', namely Process, Product, Person, Environment/Place/Press-ure. ${ }^{9}$ The newly proposed six P's formula of creativity

${ }^{6}$ John Sloboda, The Musical Mind, Oxford, Oxford University Press, 1985, 118.

7 John Sloboda, Exploring the Musical Mind, Oxford, Oxford University Press, 2005.

8 John Sloboda, The Musical Mind, op. cit., 192.

9 James C. Kaufman, Robert J. Sternberg, "Resource Review: Creativity", Change, 39, 
adds Persuasion and Potentials. ${ }^{10}$ John Sloboda developed the first psychological Model of typical compositional recourses and processes, that gave a global overview of the relevant components of the composing behaviour. The model was based on the analysis of existing research materials given by composers of tonal classical music. He brought into the model the distinction between the unconscious and conscious processes and directed his attention to two sources of composing: general tonal and stylistic knowledge and super-ordinate constraints on the form and direction that are stored in the long-term memory, and the transitory materials which constitute the successive versions of a composition as it grows in the composer's mind. The long-term knowledge as well as the repertoire of compositional devices composers have built up over the years can be applied to new compositional problems. ${ }^{11}$ Later, this model was amended by the incorporation of intentional goals and the historical context. ${ }^{12}$

In addition to this, a very well known model that has emerged from the analysis of contemporary music, is the one that refers about compositional grammar (rules of contemporary composition) which Fred Lerdahl calls "input organization" and may bear little relation to the rules of listening grammar and other intuitive constraints, which Lerdahl terms as "heard structures". ${ }^{13}$ When musical perception and cognition are fully taken into account then the compositional and listening grammars are in full alliance and that is the best music ${ }^{14}$.

Based on his experience with electro acoustical music, Emmerson offered two compositional models and suggested their relevance for any kind of contemporary music. His 'simple' model of composition has three aspects: a) Action (creating/combining sounds); b) Test (listening and determining whether they sound right together and c) accepting (storing) or rejecting

2007, 55-56; Vladislav Panić, Psihologija i umetnost [Psychology and Art], Beograd, Zavod za udžbenike i nastavna sredstva, 1997.

10 Aaron Kozbelt, Ronald A. Beghetto, Mark A. Runco, “Theories of creativity”, in: James C. Kaufman, Robert J. Sternberg (Eds.), The Cambridge Handbook of Creativity, New York, Cambridge University Press, 2010, 20-47.

11 John Sloboda, The Musical Mind, op. cit., 118-119.

12 Matthew Brown, Debussy's Iberia, Oxford, Oxford University Press, 2003.

13 Fred Lerdahl, "Cognitive constrains in compositional systems”, in: John Sloboda (Ed.), Generative Processes in Music: The Psychology of Performance, Improvisation and Composition, Oxford, UK, Clarendon Press, 1988, 231-259.

14 Ibid., 255. 
(modifying as new action). The other model incorporated New action, an Action repertoire and Reinforcement, enabling the composer to integrate, either rule based (conscious, learned) or intuitive (unconscious) action ${ }^{15}$.

\section{Generative theories of creative cognition}

Music, as well as music creation, is generally complex, generative, multilayered and hierarchical. ${ }^{16}$ To compose means to invent, imagine aural and aesthetic, structure, define sound and musical behaviour. The compositional behaviour of an individual may be characterized by the scope, precision, innovation and relationship of aural and aesthetic imagination. ${ }^{17}$ The process of making streams of sound are structured hierarchically within and across dimension; such a structure likely confers a processing advantage. ${ }^{18}$

The psychological research which would directly refer to creativity in the field of composing is rare, but there are theoretical and also empirically grounded models that could be applied and lead to understanding. One definition that summarizes many others is that creative ideas comprise three components: first, creative ideas must represent something new or innovative; second, creative ideas are of high quality, and third, creative ideas must also be appropriate to the task at hand or some redefinition of the task; thus, the creative response is novel, good and relevant. ${ }^{19}$ We are of the opinion that cognitive processes in creating music have the same general qualities as in other fields of the arts and also science. In cognitive approaches to understanding creativity, researchers try to understand the underlying mental representations, processes and mechanisms that lead to creativity. ${ }^{20}$

15 Simon Emmerson, "Composing Strategies and Pedagogy", Contemporary Music Review, 3, 1989, 133-144.

16 Jamshed J. Bharucha, Meagan E. Curtis, Kaivon Paroo, "Varieties of Musical Experience", Cognition, 100, 2006, 131-172.

17 Jonathan Impett, "Making a Mark: The Psychology of Composition", in: Susan Hallam, Ian Cross, Michael Thaut (Eds.), The Oxford Handbook of Music Psychology, New York, Oxford University Press, 2009, 403-412.

18 Catherine Stevens, Tym Byron, "Universals in Musical Processing”, in: Susan Hallam, Ian Cross, Michael Thaut (Eds.), The Oxford Handbook of Music Psychology, New York, Oxford University Press, 2009, 14-23.

19 James C. Kaufman, Robert J. Sternberg, The Cambridge Handbook of Creativity, New York, Cambridge University Press, 2010, xiii.

20 James C. Kaufman, Robert J. Sternberg, The International Handbook of Creativity, New York, Cambridge University Press, 2006, 19. 
The theoretical model concerned with the stages of the creative process, which has been extensively used, was developed by Wallas. ${ }^{21}$ It has been rephrased and made more applicable to musically creative processes. After the first, introductory or preparatory phase when the identification, understanding and defining of an aesthetic problem or assignment or intention is unfolding, as well as the first trials of problem solving, comes the second incubation phase, during which little noticeable behaviour occurs, but somehow solutions are being sought. This phase is often referred to as one which requires little awareness and when unconscious processes have to 'do their work'. Incubation ends with illumination (Aha!), when the creator experiences a sudden rush of ideas for a solution; the elaboration phase during which trial-and-error work becomes important. Trials with subsequent evaluations are repeated until an acceptable solution has been found. So, composing is constituted of iterative stages, where a product is refined successively. It is entirely conceivable that as the elaboration progresses, new problems emerge which in turn require incubation, illumination, and elaboration. ${ }^{22}$ The final phase is that of verification (or evaluation). The author employs metacognitive reflection on the process and strategies, and verifies/checks out whether the solution that he/she came up with is the right one. ${ }^{23}$

The theoretical model that strives to explain the place and role of cognitive processes in the understanding of music as well in the conceptualizing and creating of music was elaborated by Lawrence M. Zbikovski. ${ }^{24} \mathrm{He}$ emphasizes the complex, multileveled and hierarchical organization of processes and cognitive operations which take place during the creation of music. Understanding music is not simply a matter of processing auditory signals - it involves a number of higher-order processes. These processes include, but are not limited to, categorization (of musical fragments, motifs as basic level categories and it goes up to the hierarchical level), cross-domain mapping (the metaphorical nature of our descriptions of musical events), and the use of conceptual models (crucial for explaining the larger context for judgments

21 Graham Wallas, The Art of Thought, New York, Harcourt, Brace, 1926.

22 Andreas C. Lehmann, John A. Sloboda, Robert H. Woody, Psychology for Musicians. Understanding and Acquiring the Skills, New York, Oxford University Press, 2007, 133.

23 Aleksandar Kostić, Kognitivna psihologija [Cognitive Psychology], Beograd, Zavod za udžbenike, 2010, 402.

${ }^{24}$ Lawrence M. Zbikowski, “The Cognitive Tango”, in: Mark Turner (Ed.), The Artful Mind: Cognitive Science and the Riddle of Human Creativity, New York, Oxford University Press, 2006, 115-132. 
about how musical events relate to one another and to capture the uniquely cultural aspect of music). Conceptual models are relatively basic cognitive structures that act as guides for reasoning and inference. ${ }^{25}$

When writing about processes that take place while music is created, Sloboda referred to two subsequent stages: the first he called 'inspiration' where a skeletal idea or themes appear in consciousness and the second called 'execution' where the ideas are subject to a series of more conscious and deliberate processes of extensions and transformation. ${ }^{26}$ Another, also two-stage model, which has a seminal role in the theoretical concept of creative cognition, is focused on the creative processes and structures that underlie creative thinking. This model could also be applied to compositional processes, and is referred to as the Geneplore model. ${ }^{27}$ The authors were of the opinion that traditional models with categorization do not specify exactly how an individual imagines or generates a novel instance of a category. The two main processing stages in a creative thought are: the generative and the exploratory phase. In the first one, an individual produces an idea, constructs mental representations, referred to as 'pre-inventive structures', which can promote creative discoveries and is certainly characterized by divergent thinking. In the exploratory phase, these properties are used to expand creative potential and come up with creative ideas. Later on, the authors formulated Creative cognition approach ${ }^{28}$ which is concerned with explaining how fundamental cognitive processes, available to virtually all humans, operate on stored knowledge to yield ideas that are novel and appropriate to an impending task. ${ }^{29}$ Attempts at approaching creative cognition endeavour to identify the detailed operations of those component processes and its outcomes. It is in its nature convergent, and seeks for the depth of the cognitive processes. The authors speak about structured imagination as creative cognition.

25 Lawrence M. Zbikowski, "Modelling the Groove: Conceptual Structure and Popular Music", Journal of the Royal Musical Association, 129, 2004, 2, 272-297; Lawrence M. Zbikowski, Conceptualizing Music: Cognitive Structure, Theory, and Analysis, New York, Oxford University Press, 2002.

${ }^{26}$ John Sloboda, The Musical Mind, op. cit., 116.

27 Ronald A. Finke, Thomas B. Ward, Steven M. Smith, Creative Cognition: Theory, Research and Applications, Cambridge, MA, MIT Press, 1992.

28 Steven M. Smith, Thomas B. Ward, Ronald A. Finke, The Creative Cognition Approach, USA, MIT Press, 1997.

29 Thomas B. Ward, Yuliya Kolomyts, “Cognition and Creativity”, in: James C. Kaufman, Robert J. Sternberg (Eds.), The Cambridge Handbook of Creativity, New York, Cambridge University Press, 2010, 93-112. 
The generative processes, as identified, could be the retrieval of various types of information, mental synthesis, mental transformation and then, the retrieval of an example, general knowledge, mental imagery, the analysis of features, abstraction, analogy, episodic memory retrieval, as well as associations. These processes give rise to pre-inventive structures (may consist of imagined forms, mental models or designs, examples for novel or hypothetical categories), which are then used or interpreted in the exploratory stage, by examining their emergent properties and considering their implications (processes such as associations, retrieval, synthesis, transformation and analogical transfer). In that phase, creativity (e.g. enhancing incubation with contextual manipulations; awareness, the challenging of probe elements) and memory (e.g. metacognitions about impending recall) have their roles. Memory can be activated through hierarchical organized schemas, in the case that nodes/concepts have some levels of energy or excitement and are related by links, or they can be activated by spreading through associations between semantically related concepts, as explained by spreading the activation model. Memory could be even more complexly activated through a parallel distributing processing network of nodes/concepts and links. ${ }^{30}$

After the exploratory phase is completed, the pre-inventive structures can be refined or regenerated in the light of discoveries and insights that may have occurred. There may be several cycles of creation, the process can be repeated, until the pre-inventive structures result in a final, creative idea or product ${ }^{31}$. The authors listed a wide range of processes that are crucial for creativity, nevertheless they are engaged in the generative or exploratory phase: insights (perceptual-restructuring ability, field dependence, or based on preexisting knowledge), extending concepts (extending, elaborating, on the basis of new experiences new ideas are developed), recently activated knowledge (by recent experiences, interference, inhibition, involuntarily mental blocks), conceptual combination (novel combination of concepts), creative imagery (generation of creative inventions), ${ }^{32}$ and fundamental cognitive processes,

30 Daniel T. Willingham, Cognition, New Jersey, Pearson Education International, 2007, 249-257.

31 Steven M. Smith, Thomas B. Ward, Ronald A. Finke, op. cit., 193-206.

32 Thomas B. Ward, Steven M. Smith, Ronald A. Finke, "Creative Cognition", in: Robert J. Sternberg (Ed.), Handbook of Creativity, Cambridge, Cambridge University Press, 2004, 189-212. 
such as abstraction, conceptual combination and analogy. ${ }^{33}$ A particular domain of interest is the explanation of creativity as a conceptual combination, a process whereby previously separate ideas, concepts, or other forms are mentally merged, but they are not mere summations of the elements. Instead, they can yield emergent features. ${ }^{34}$

\section{Composing music as a metacognitive behavior}

The process of knowing and applying metacognitive strategies in composing shares its characteristics with a social cognitive concept of self-regulative learning. ${ }^{35}$ Central to the concept of metacognition is thinking about one's own thoughts. It can be thinking of what one knows (i.e. metacognitive knowledge), what one is currently doing (i.e. metacognitive skill) or what one's current cognitive or affective state is (i.e. metacognitive experience). ${ }^{36}$ Metacognitive strategies engaged in a process of composing are, as in other cognitive activities, concerned with planning, monitoring and evaluation of the results. ${ }^{37}$ One of the often mentioned and empirically grounded distinctions between strategies composers use is goal-oriented versus exploratory. ${ }^{38}$ Similarly, Bahle's ${ }^{39}$ well known analysis of approaches and strategies composers apply, made a distinction between 'working types' and others whom he called 'inspirational types'. Those two differ in how they find and solve musical problems, what working method they employ, and how they assess their products. The inspirational type is less conscious about the working process,

33 Thomas B. Ward, Yuliya Kolomyts, “Cognition and Creativity”, op. cit., 96.

34 Ibid., 101.

35 Gary McPherson, Barry J. Zimmerman, "Self-regulation of Musical Learning”, in: Richard Colwell \& Carol Richardson (Eds.), The New Handbook of Research on Music Teaching and Learning, Oxford, Oxford University Press, 2002, 327-347.

36 Douglas J. Hacker, “Definitions and Empirical Foundations", Douglas. J. Hacker, John Dunlosky, Arthur C. Graesser (Eds.), Metacognition in Educational Theory and Practice, London, Lawrence Erlbaum Associates, 1999, 3.

37 Susan Hallam, "The Development of Metacognition in Musicians: Implications for Education", British Journal of Education, 18, 2001, 1, 27-39; Harald Jorgensen, Susan Hallam, "Practicing", in: Susan Hallam, Ian Cross, Michael Thaut (Eds.), The Oxford Handbook of Music Psychology, New York, Oxford University Press, 2016, 449-465.

38 Thomas B. Ward, Steven M. Smith, Ronald A. Finke, op. cit., 207.

39 Julius Bahle, Der musikalische Schaffensprozeß: Psychologie der schöpferischen Erlebnis - und Antriebsformen, Konstanz, Germany, Paul Christiani, 1947/1982. 
experiencing the source of ideas and solutions as relatively random and coming from the outside, while the working type toils systematically and experiences the product as a direct result of such efforts. ${ }^{40}$

Radocy \& Boyle ${ }^{41}$ gave a short review of 12 contemporary composers' reported approaches to composition, essentially referring to their metacognitive strategies. These were: creating geometric shapes or designs which provide a skeletal framework for melodic, harmonic and rhythmic concepts (Andrzej Panufnik); compositional planning by using mathematical processes from theories of probability, calculus, game theory, mathematical logic and set theory (Iannis Xenakis); the conceptualization of an entire work before starting and keeping this Gestalt in mind throughout the compositional process (Glenn Branca); planning the overall structure of the composition prior to beginning (Karlheinz Stockhausen); 'mapping out' the entire composition, including the length and formal structure (Sir Michael Tippett); the general plan for overall work, though many details are done during the process, including sketches of possible solutions (Elliott Carter); the overall conception of the work and 'key ideas' as a basis (Witold Lutoslawski); planning the formal structure usually related to previous or forthcoming compositions in order to continuously create a larger structure (Dennis Kam); the collection of periodically sketched ideas, themes, patterns, later on coming back to them (David Del Tredici); the process based on memorized non-musical sounds, which the composer collects, combines and then recombines in a musical context, using a 'snowball of sounds' method (Robert Erikson); using three bases for pre-compositional planning: the program (storyline, picture), shapes of the outline for the overall drama and formal structure and 'figure themes', such as motives or thematic materials (Sherwood Shaffer); concern with a composition as a process in and of itself, extensive pre-planning seems less important (Steve Reich). So, composers have their pre-compositional strategy as an idea and/or organizing basis for their compositions, and those correspond very well with the concept of metacognitive strategies, and especially with 'top-down' (8 composers) and 'bottom up' organization of musical thinking (4) and no exact plan (1).

More recent research, which also points out two kinds of thinking processes during creating music was reported from the results of an observa-

\footnotetext{
40 Andreas C. Lehmann, John A. Sloboda, Robert H. Woody, op. cit., 132.

41 Rudolf E. Radocy, J. David Boyle, Psychological Foundation of Musical Behavior (4 ${ }^{\text {th }}$ edition), Springfield, Illinois, Charles C. Thomas, Publisher Ltd., 2003, 299-300.
} 
tional case-study, based on qualitative data comprised of stimulated recall interviews conducted in the composer's studio during the compositional process and the entire manuscript corpus that the composer created during that process. The aim was to explore the dynamics and functions of two generative strategies in thinking, intuitive and reflective modes. The results showed the qualitative change in the composer's intuitive and reflective thinking in the course of the process; within intuitive compositional acts, imagination changed into experimentation and incubation into restructuring, whereas within reflective compositional acts, rule-based reasoning changed into contemplating alternatives. Further, intuitive metacognition decreased while reflective metacognition increased. In the grounding procedure, the composer substantiated the fuzzy construction of his original ideas into aesthetically coherent musical structures that gradually limited the compositional problem space. The rationalization procedure involved the composer becoming increasingly proficient in the way in which he worked on his musical ideas and materials. ${ }^{42}$

Composers have knowledge of metacognitive strategies for elaborating and structuring music material or ideas when formulating pre-inventive structures or streaming towards the final version of the musical work. Our findings showed that in the composing process, two basic strategic approaches, cognitive (predominant) or imaginative, or either 'bottom-up' or 'topdown', were confirmed. ${ }^{43}$ The first one relies on the composer's cognitive and creative capacities, but it is highly dependent on knowledge and experience while the second one keeps in touch with fantasy and spontaneity ${ }^{44}$.

\section{Relation between creativity, knowledge and novelty}

We are of the opinion that previously mentioned generative models of creative cognitive practices in composing, integrate the impact of long-term knowledge structures that are, when needed, drawn intentionally or intuitively from a long-term memory. Weisberg supports the opinion that there can-

42 Ulla Pohjannoro, "Capitalizing on Intuition and Reflection: Making Sense of a Composer’s Creative Process”, Musicae Scientiae, 20, 2016, 2, 207-234.

43 Tijana Popović Mladjenović, Blanka Bogunović, Ivana Perković, "Nature versus Culture: Compositional Practices of Contemporary Serbian Composers", in: Tijana Popović Mladjenović, Blanka Bogunović, Ivana Perković, Interdisciplinary Approach..., op. cit., 133-188.

44 Ibid., 166. 
not be any creativity if a product is not strongly rooted in the past. Without some sort of frame of reference to the past there will be no coherence and the product will make no sense to the audience. ${ }^{45}$ Hayes $^{46}$ demonstrated that well-known and productive composers also needed about 10 years from the start of training to entrance into the profession, when making significant creative production, regardless of their starting age.

A very interesting study, where the historiometric method was used, confirms these statements. A comprehensive analysis was made of Ludwig van Beethoven's explicit self-criticisms of 70 compositions he made during his lifetime, spanning his whole career and most musical forms. The result showed that his comments are likewise largely consistent with expert ratings and recording counts. The results suggest considerable self-critical acumen on Beethoven's part and support an expertise view of musical creativity in which knowledge and experience are likely to enable both progressively greater creative accomplishments and sounder self-criticism ${ }^{47}$.

The creative cognition model, focuses on the cognitive ingredients of the creative process and is consonant with the broadly agreed notion that existing knowledge plays a role in creativity at all levels, and that quality of the creative outcomes will be influenced by the extent of the person's knowledge and the manner in which the elements of that knowledge are accessed and combined ${ }^{48}$. Domain background knowledge enables the classification of the problem, allows better perception of the most important part of the problem and thereby restricts the search to the key part of the problem space. Secondly, it helps problem solving by automatizing some of the problem-solving steps, so they do not demand attention. ${ }^{49}$

Robert Weisberg states that prior to a significant contribution to a creative discipline one first has to achieve deep initial immersion in that discipline. Also, for his/her knowledge to be used in creative thinking, innovation,

45 Robert W. Weisberg, "Creativity and Knowledge: A Challenge to Theories", in: Robert J. Sternberg (Ed.), Handbook of Creativity, Cambridge, Cambridge University Press, 2004, 226-250.

${ }^{46}$ John R. Hayes, The Complete Problem Solver (2 ${ }^{\text {nd }}$ edition), Hillsdale, NJ, Erlbaum, 1989.

47 Aaron Kozbelt, "A Quantitative Analysis of Beethoven as Self-critic: Implications for Psychological Theories of Musical Creativity”, Psychology of Music, 35, 2007, 1, 144-168.

48 Thomas B. Ward, Yuliya Kolomyts, op. cit., 3-94.

49 Daniel T. Willingham, op. cit., 382. 
no matter how radical, it has to have a link to what has been done before, in order to make sense for the creator. ${ }^{50}$ Further on, Weisberg discusses the relation between knowledge and creativity as a heuristic thinking process that is rooted in the existing knowledge of the field. Still, there is a question of specifying how knowledge is actually used in creative thinking. The question is, to which extent creative products can be influenced by features that are depicted/heard by previously seen/ heard examples. On the other side, previous knowledge can also hinder innovation, it can hurt the creative cognition. ${ }^{51}$ Since the most recent theorizing concerning creative thinking has been based on the tension view, which refers to the inverted-U-shaped relationship between formal education and creative accomplishment (meaning that the creative product is an output of optimal level of those two), the main concern has been with understanding how the thinker can break away from knowledge. ${ }^{52}$ This issue was also covered by Mandler, ${ }^{53}$ who explains the 'mind-popping' effect that has its basis in the apparently facilitating role of a preconscious mental content and conversely, but it is exposed to the possible restricting role of conscious material. In other words, activated representations of which we are not aware produce a wider spread of activation than those of conscious material, because awareness inhibits mind-pop ups and novelty ideas. On the other hand, prior knowledge can impose existing patterns of problem solutions and cause functional fixation and hence disable insight into possible solutions (e.g. in a form of mind-popping effects).

What happens just before novelty appears? At the time that the problem is established (prior to the mind-popping event), target structures and candidate responses continue to activate other structures and representations and these are periods of incubation. In the case of mind-popping, such activation occurs more easily and widely than under conditions when active searches of consciousness are taking place. That term has primarily been applied to problem solving tasks in which the unsuccessful attempt at a solution are followed by a pause or delay, after which successful solutions are more probable. ${ }^{54}$

\footnotetext{
50 Robert W. Weisberg, op. cit., 246.

51 Thomas B. Ward, Steven M. Smith, Ronald A. Finke, op. cit., 200.

52 Robert W. Weisberg, op. cit., 242.

53 George Mandler, “Origins and Consequence of Novelty", in: Steven M. Smith, Thomas B. Ward, Ronald A. Finke (Eds.), The Creative Cognition Approach, USA, MIT Press, 1997, 9-26.

54 Ibid., 17.
} 
Weisberg also specified that deep immersion provides extensive opportunities for practicing any skills, required to create within the domain, which makes them automatic. Automaticity of skills may be necessary to produce novelty. However, this speculation does not specify how automaticity leads to novelty. Perhaps when a skill becomes automatic one can then allocate capacity to the production of novelty. One doesn't have to think about how to express one's ideas; one just does it as the ideas become available. This view proposes that the value of immersion is to perfect the skill, so that performing it does not drain capacity. Deep immersion might also lead to the development of heuristics. ${ }^{55}$ The automatic creation of ideas is also associated with the implicit (which does not depend on conscious recollection) and the explicit (which involves conscious recollection) memory, as well as to related concepts of the declarative ('knowing that') and procedural memory ('knowing how'). ${ }^{56}$

So, there is a relation between immersion, knowledge, the production of heuristic ideas and the cognitive strategies of problem solving. ${ }^{57}$ Several authors refer to problem solving and space-searching models (which include all possible configurations a problem can take) as a place where some form of the heuristic directs the process. ${ }^{58}$ The problem solving heuristic is 'like hill climbing, one looks for an operator that will bring a person to the problem space that is closer to the goal of the thinking process. The heuristic in problem solving is a simple rule that can be applied to a complex problem. ${ }^{59} \mathrm{Com}$ positional strategies for solving problems are seen through patterns, where particular musical problems have been addressed by either general or specific solutions, or by 'insightful' restructuring processes. ${ }^{60}$ The role of imagination in exploring possible compositional solutions/the probing of possible space is by the imagining of alternatives to a given reality and how imagination works by exploring the parameters along which it could be otherwise. ${ }^{61}$

55 Robert W. Weisberg, op. cit., 247.

56 Aaron L. Berkowitz, The Improvising Mind. Cognition and Creativity in the Musical Moment, New York, Oxford University Press, 2010, 8.

57 John R. Hayes, op. cit.

58 Jonathan Impett, op.cit.

59 Daniel T. Willingham, op. cit., 376.

60 Tijana Popović Mladjenović, Blanka Bogunović, Ivana Perković, Interdisciplinary Approach..., op. cit.

61 Ruth M. J. Byrne, The Rational Imagination: How People Create Alternatives for Reality, Cambridge MA, MIT Press, 2005. 
The question that is often posed is, whether novelty construction is deliberate or unintentional activity? The deliberate creation of novelty introduces another dimension of creativity - the kind of goal or end state required. One of the situations is problem solving situations that call for some degree of creativity. In that case, the search for novelty requires some prior notion as to the kind or type of solution that is required, followed by the search for a token that fits the problem encountered. If the particular goal exists, then the act of creation is deliberate in the long term, though it may be non-deliberate at the moment of production, while the solution may come to mind unexpectedly. ${ }^{62}$

The other case, when novelty is produced, is the production of dreams like those which are not goal-directed, and therefore non-intentional, and unconscious, but usually creative and novel productions. So, dreams are, mainly, novel constructions/reconstructions of previously registered and encoded knowledge and experience and are therefore characterized by some aspects of creative thought. Without the structure of the real world, the building blocks of dreams are floating and free to be organized by high-order structures that may combine quite separate, unrelated thoughts about events. But, since there are no real-world constraints, they may be combined into sequences and categories by activating higher-order schemas to which they are relevant. This happens, either because there is a general tendency to classify and order mental contents or schemas, tending to fill in the values of their features whenever possible. ${ }^{63}$

\section{Creative processes in context}

Cognitive processes and knowledge are one way or another, addressed in a variety of confluence models that refer broadly to the range of contributing factors among them, social and cultural. Viewing art as an evolutionary phenomenon, cognitive psychologist Merlin Donald considered art to be inherently metacognitive in its cognitive function on both the individual and social levels. In his opinion, art always occurs in the context of the distributed cognition of culture and is always aimed at a cognitive outcome. ${ }^{64}$

62 George Mandler, op. cit., 11.

63 Ibid., 14.

${ }^{64}$ Merlin Donald, “Art and Cognitive Evolution”, in: Mark Turner (Ed.), The Artful Mind: Cognitive Science and the Riddle of Human Creativity, New York, Oxford University Press, 2006, 11-19. 
Csikszentmihalyi's systems theory of creativity, belongs to a group of confluent ones, focused less on the creative person but involving multiple factors. He included three interacting components: a) the domain or body of knowledge that exists in a particular discipline at a particular time; b) the individual, who acquires domain knowledge and produces variations on existing knowledge; c) the field, comprised of other experts and members of the discipline, who decide which novelties in that discipline are of worth for the next generation. So, he included the individual, domain and field, where the individual uses an acquired domain of knowledge along with cognitive abilities to make advances to domains, whose worth is judged by gatekeepers of the domain or field. ${ }^{65}$ In addition, authors from the field of the social psychology of music refer to composing as a process and activity, which has its individual creative, imaginational, emotional and cognitive sources and personal history, which are founded in a social-psychological context that determines the achievement, motivation, and identity of the composer. ${ }^{66}$

Unlike Csikszentmihalyi's systems theory, where the accent is placed on an evolving milieu, the evolving-systems approach to creativity is primarily an account of what creators do and understanding their unique attributes. The evolving-systems approach focuses less on understanding what particularly fits into the context of an individual creator's goals, knowledge and reasoning, as well as larger social forces and creative paradigms. Gruber and Wallace introduced several foundational concepts: an ensemble of metaphors that great creators likely use in their thinking, which together characterize a developmental process that leads to making creative meaning, not relying on a single one. Another concept is that of a network of enterprises, a system of goals describing how an eminent creator may work on seemingly disparate projects, consecutively or concurrently and continually evolve a sense of relations between the topics. ${ }^{67}$

The well-known historimetric research of Dean Simonton, who investigated the truly life-span histories of extraordinary creative individuals,

65 Mihaly Csikszentmihalyi, "Implications of a Systems Perspective for the Study of Creativity”, in: Robert J. Sternberg (Ed.), Handbook of Creativity, Cambridge, Cambridge University Press, 2004, 313-335.

66 Adrian C. North, David J. Hargreaves, The Social and Applied Psychology of Music, New York, Oxford University Press, 2008.

${ }^{67}$ Howard E. Gruber, Doris B. Wallace, "The Case Study Method and Evolving Systems Approach for Understanding Unique Creative People at Work”, in: Robert J. Sternberg (Ed.), Handbook of Creativity, Cambridge, Cambridge University Press, 2004, 93-115. 
among them composers, started from the position that creativity operates in the social context. Simonton took into account massive and impersonal influences from the Zetgeist or Ortgeist and grouped them into four categories: cultural factors, societal factors, economic and political factors. These factors define the milieu in which talented youth grows, in such a way that they shape both, the nature and the level of creative accomplishments of the future extraordinary adult. ${ }^{68}$ The computerized content analysis of musical structure revealed a great deal about the psychology of musical aesthetics and creativity in a study where biographical information about 479 composers of classical music were considered ${ }^{69}$ (Simonton, 1994). Simonton found out that biographical stress and physical illness served to heighten levels of melodic originality, though the 'swan-song-phenomenon' revealed that the proximity of the composers' death diminished melodic originality. ${ }^{70}$

Another historiometric study was done by Kozbelt, who applied computer analysis to the ratio between performance time productivity and versatility estimates for 102 classical composers. The results pointed out that greater productivity was associated with greater versatility, but only among Baroque- and Classical-era composers, while the average annual productivity then decreased, along with eminence, throughout the Romantic era. Why was that? Kozbelt explains that, earlier composers were often required to write a great quantity of music simply to make their living or reputation and they could gradually develop a style by composing numerous rather similar works. In contrast, later composers, especially in the 20th century, have on average written less music overall but have simultaneously composed in a wider variety of genres; they have also had to respond to greater pressure for novelty than earlier generations did. This appears to have favored composers who are rather rapidly able to find new means of expression. Because of lower productivity and greater versatility compared to earlier eras, these new means of expression are typically not evolved over long series of simi-

68 Dean K. Simonton, “Creativity from Historiometric Perspective”, in: Robert J. Sternberg (Ed.), Handbook of Creativity, Cambridge, Cambridge University Press, 2004, 116133.

69 Dean K. Simonton, "Computer Content Analysis of Melodic Structure: Classical Composers and Their Compositions", Psychology of Music, 22, 1994, 31-34.

70 Dean K. Simonton, "Emotion and Composition in Classical Music: Historiometric Perspectives", in: Patrik N. Juslin, John A. Sloboda (Eds.), Music and Emotion. Theory, Research, Applications, Oxford, Oxford University Press, 2010, 347-366. 
lar compositions. ${ }^{71}$ Galenson speaks of these kinds of art creators in several domains, designating them as conceptual innovators or finders. Galenson discovered that these individuals frequently create their most renowned works at relatively young ages. ${ }^{72}$ These findings are in accord with those reported by Simonton, ${ }^{73}$ who found that historically more recent composers showed a tendency to have written their most renowned work at younger ages. In line with these findings is the opinion of Marc Leman, musicologist, who explains the rise of avant-garde composers with the advent of new conditions for musical creativity which can be explained by a combination of factors, involving state-of-the-art science and technology, the development of mass media, the politics of state-supported music production institutions (field), and - last but not least - the artistic developments that imposed an antiromantic modernist (globalist) view of music as a high-culture phenomenon (domain) ${ }^{74}$

\section{Interdisciplinary research in creativity, cognition and composing music}

After the 'first call' of John Sloboda ${ }^{75}$ (1985) for psychological research in composing music, the situation did not change much in some 20 years. But, after that, the state of affairs started to evolve. A new research paradigm in 'art and science' emerged, as well as 'interdisciplinarity' in diverse collaborative settings. New paradigms, which at some moments come together, were defined as artistic exploration and scientific investigation. The first exploits the creative processes, using tools that allow the flexible control and manipulation of musical materials, while the second one systematically investigates the

\footnotetext{
71 Aaron Kozbelt, "Performance Time Productivity and Versatility Estimates for 102 Classical Composers", Psychology of Music, 37, 2009, 25-46.

72 David W. Galenson, Old Masters and Young Geniuses, Princeton, NJ, Princeton University Press, 2005; David W. Galenson, Painting Outside the Lines: Patterns of Creativity in Modern Art, Cambridge, MA, Harvard University Press, 2001.

73 Dean K. Simonton, "Emergence and Realization of Genius: The Lives and Works of 120 Classical Composers”, Journal of Personality and Social Psychology, 61, 1991, 829840.

74 Marc Leman, “Musical Creativity Research”, in: James C. Kaufman, John Baer, Creativity Across Domains: Faces of the Muse, Boca Raton, Psychology Press, 2011, 103-122. 75 John Sloboda, The Musical Mind, op. cit.
} 
creative process. ${ }^{76}$ Duality between cognitive psychology and music(ology) as to focus/discourse and methodologies in the research of creative musical activity, was shaken by Irene Deliège and Geraint Wiggins, who claimed that it was time to 'get rid of creativity and look at creative acts. ${ }^{\text {' }} 7$ This statement encouraged the study of creation based upon direct observation in sufficiently natural circumstances and strongly supported by computational technologies.

Interdisciplinarity in the field of the psychology of music grew to the point that it overlapped with many disciplines and this trend had its implications in the research of creative cognition in composing music. ${ }^{78}$ The heterogeneous and constantly evolving nature of musicological discourse provided a space for those who were seeking to adopt a psychological approach. ${ }^{79}$ So, Nicolas Donin proposed to 'cross-fertilize' empirical and historical musicologies, based on his work on contemporary compositional processes. ${ }^{80} \mathrm{~A}$ new book edited by Dave Collins, The act of musical composition. Studies in the creative process, ${ }^{81}$ has collected the newest research on composition, from different angles and disciplines.

So, what we now have is a rich 'art and science scenery' that gives its fruits - new issues, new methodologies and new results: artistic exploration which uses creativity in the process of making a musical piece, the observation of the creative act and the investigation of the creative process with the emphasis on cognitive processes. In all three research discourses computational

\footnotetext{
76 Marc Leman, op. cit., 103.

77 Irène Deliège, Marc Richelle, "Prelude: The spectrum of Musical Creativity", in: Irène Deliège, Geraint A. Wiggins (Eds.), Musical Creativity: Multidisciplinary Research in Theory and Practice, New York, NY, Psychology Press, 2006, 1-6.

78 Susan Hallam, Ian Cross, Michael Thaut, The Oxford Handbook of Music Psychology, New York, Oxford University Press, 2009.

79 Adam Ockelford, "Beyond Music Psychology", in: Susan Hallam, Ian Cross, Michael Thaut (Eds.), The Oxford Handbook of Music Psychology, New York, Oxford University Press, 2009, 539-551.

80 Nikolas Donin, Caroline Traube, "Tracking the Creative Process in Music: New Issues, New Methods", Musicae Scientiae, 20, 2016, 3, 283-286; Nicolas Donin, "Empirical and Historical Musicologies of Compositional Processes: Towards a Cross-fertilization", in: Dave Collins (Ed.), The Act of Musical Composition: Studies in the Creative Process, Farnham, UK, Ashgate, 2012, 1-26.

81 Dave Collins, The Act of Musical Composition. Studies in the Creative Process. SEMPRE Studies in the Psychology of Music, New York, Routledge, 2016.
} 
technology is the sine qua non, as well as methodological rigour and an empirical approach. The new research methodology has been formulated with the intention of raising objectivity, as much as possible, which is more appropriate to facing the challenge of investigating the complex, personal and multilayered process of composing. In the following part of this article we shall briefly present the most recent and relevant results, of the 'new age' authors.

\section{New technology in music creation}

Music creation requires the knowledge of particular non-musical skills in acoustics, psychoacoustics, electronics, and computing and that has enabled the emergence of new models of creative cognition in composing: a network of computers with a digital audio, but also software or tools that allow the manipulation of information, focused on concrete sound phenomena and perception-based processing, abstract composition and metaphors, the perception and timbre-based approaches, and the Spectro morphological paradigm, whereas the focus on abstract composition and metaphors has been further developed in more Artificial Intelligence-oriented approaches. ${ }^{82}$ Besides, the development of computer programs for composing music is available. ${ }^{83} \mathrm{But}$, as Leman remarked, all software tools constrain the creation process in the sense that the creator has to follow the logics of the software developer in order to master its creative possibilities. Nevertheless, it is clear that the 'new time' of research requires new and wider knowledge and skills of the composer that can be accomplished in collaboration with other disciplines.

\section{Case-studies of the creative act}

The prevailing method for observational studies is the case-study where the researcher, due to the good contact or friendship or deserved trust of a composer, is entitled to 'come closer' and observe the creative process. In those cases, the methodology is qualitative - consisting of gathering personal reports during the process. The most difficult constraint is that the composer cannot create and talk simultaneously because the process is disturbed, and only sketches are not enough. A post festum interview disturbs the picture.

82 Marc Leman, op. cit., 103-122.

${ }^{83}$ Marcus Pearce, David Meredith, Geraint Wiggins, "Motivations and Methodologies for Automation of the Compositional Process", Musicae Scientiae, 6, 2002, 2, 119-147. 
So, new research procedures have been developed, in almost natural 'ecological' conditions, in order to diminish any disturbance as much as possible and obtain objective and reliable data. One of the studies brought a new method which is based on stimulated recall interviews conducted in the composer's studio during the compositional process and on the entire manuscript corpus that the composer created during that process (sketches, notebooks drafts, computer files). ${ }^{84}$ Similar to that, a situation simulation method was developed, when the audiovisual media and recorded interview were used in order to efficiently document the collective task of reconstructing a past activity. During the 'compositional situation simulation interview', the composer sat before his manuscript in order to induce his recollection, simulation and verbalization of the completed creative act. The idea is to reassemble the creative process by documenting the cognitive and artistic characteristics of each successive moment and operation, in order to understand the composer's course of action and act that unfolds both consciously and subconsciously, stretching beyond the time of each connected task. ${ }^{85}$

A nice example of successful collaboration between the psychologist and composer gave hope for interdisciplinary research. The project was designed with the goal of observing the process of composing the Angel of death for piano, chamber orchestra and computer-processed sound, by Roger Reynolds, from its initial conception to its concert premiere. The methodology covered the examination of written manuscripts (sketches and notebooks), the examination of what the composers say about their compositional process, and observation during a session of composition. ${ }^{86}$ The results gave material for discussion about the aspects of solving a compositional problem, the types of representations and their generalizability. The composer reported about experiences in the procedural and perceptual aspects of musical experimentation, the motivations and strategies that underlie musical innovation. ${ }^{87}$

\footnotetext{
84 Ulla Pohjannoro, op. cit.

85 Nicolas Donin, François-Xavier Féron, “Tracking the Composer's Cognition in the Course of a Creative Process: Stefano Gervasoni and the Beginning of Gramigna”, Musicae Scientiae, 16, 2012, 3, 262.

86 Stephen McAdams, "Problem-solving Strategies in Music Composition: A Case Study”, Music Perception, 21, 2004, 3, 391-429.

87 Roger Reynolds, "Compositional Strategies in the Angel of Death for Piano, Chamber Orchestra and Computer-processed Sound", Music Perception, 22, 2004, 2, 173-205.
} 


\section{New technology in scientific studies analyzing the creative process}

Artificial intelligence and the music approach use computer technology to develop models of human cognitive processes when engaged in musical activity. ${ }^{8}$ Also, neurocognitive studies were done with composers, which researched the regions of their brain, while they were performing the musical task of composing a piece, using an electroencephalograph (EEG), positron emission tomography (PET) and functional magnetic resonance imaging (fMRI). ${ }^{89}$ In these experimental or qualitative studies, the number of participants were small.

New techniques of computer-based data collection were developed in order to study compositional processes 'on-line' and to follow up the musical procedures and process of making cognitive decisions during creating music. By highlighting music composition as a 'dynamic' time-related process, Kratus $^{90}$ suggested that in the analysis of compositional activity, researchers should trace changes in the process over time and implemented computer-based data collection techniques in order to track such changes. Collins gave a thorough listing of studies that employed computer-based data collection techniques, not only in a process of data gathering, but also in registering processes such as creative problem solving, the relationships between the graphical, figural representation of sounds and cognitive processes, tracking compositional strategies, which authors define as 'significant decision-making moments for the overall composition', videotape to track 'phases' in the compositional process: the exploratory, rehearsal and construction phases. Collins himself conveyed a three-year single case study in order to track the compositional process in real time. A combination of data collection techniques was used to attempt to map cognitive processes: digital MIDI save-as files, analogue audio files, semi-structured interviews, immediately retrospective verbal accounts and verification sessions between the composer and the researcher. The findings indicated a chunking of processes and strategies at the micro and macro levels. The results of this study point to a generative process of problem proliferation and successive solution implementation, occurring not only in a linear manner, but also recursively. The moments of creative

${ }^{88}$ Mira Balaban, Kemel Ebcioglu, Otto E. Laske (Eds.), Understanding Music With AI: Perspectives on Music Cognition, Menlo Park, CA, The AAAI Press, 1992, 182.

89 Elvira Brattico, Mari Tervaniemi, "Musical creativity and the human brain”, in: Irène Deliège, Geraint A. Wiggins (Eds.), Musical Creativity..., op. cit., 290-321.

90 John Kratus, "A Time Analysis of the Compositional Processes Used by Children Ages 7 to 11", Journal of Research in Music Education, 37, 1989, 1, 5-20. 
insight were observed that were related to Gestalt theory problem restructuring; some were seen to overlap in real time with others, indicating an element of parallelism in creative thinking ${ }^{91}$.

In another study, the participants created their music at the computer workstation, MIDI files were continuously collected using the 'save-as' command. This novel approach allowed a more accurate degree of mapping compositional processes, as each 'save-as' could be accompanied by a date and time stamp within the file, rather than erasing previous work. Folkestad suggested two fundamental styles of composition: horizontal, where the melody, harmony and structure are composed in one activity from beginning to end, and smaller scale editing procedures such as the instrumentation deployed afterwards, and vertical, where the composer works in small chunks, completing them before moving on to the next section. ${ }^{92}$

The problem of the generalization of research findings is present, because of primarily case-study methods and the idiosyncratic nature of the process. So, a research design in an interesting study with eight composers tried to deal with the problem of generalization. Eight professional composers were studied in a real-world setting in search of broad compositional activities that are both common to the composers studied, and that are meaningful for individual compositional processes. The aim was to compare individual creative processes in music composition, across aesthetic visions, research concepts, data collection and analysis methods. To apply similar criteria in the analysis of eight creative processes, an analysis framework was proposed, consisting of four main compositional activities (planning, exploring, writing and rewriting) and three attributes (productivity, level of musical abstraction and creativity). The results of the study showed how the eight processes were individually characterized by a specific configuration, that is, the four main compositional activities appeared in a selective presence, chronological order and hierarchy. Although no activities or strategies common to all eight composers were found, some configurations were also recognized in creative processes outside the study. ${ }^{93}$

91 Dave Collins, "A Synthesis Process Model of Creative Thinking in Music Composition", Psychology of Music, 33, 2005, 2, 193-216.

92 Göran Folkestad, David J. Hargreaves, Berner Lindström, "Compositional Strategies in Computer-based Music Making”, British Journal of Music Education, 15, 1997, 1, 8398.

93 Hans Roels, "Comparing the Main Compositional Activities in a Study of Eight Composers”, Musicae Scientiae, 20, 2016, 3, 413-435. 


\section{Conclusion}

This overview acquired a kind of quasi historical dimension, because it presents a wide scope of themes, theoretical models, knowledge and authors in a period of some 35 years, since 1985. The above listed and explained theoretical concepts and empirically gained knowledge from the interdisciplinary fields of music psychology, creativity research, cognitive psychology, musicology and the experiences and thoughts of artists, give the basic schemata or template for understanding and analyzing the creative cognition processes in producing contemporary art music.

The leading role of cognitive processes in music creation has been confirmed. Next to that, we are of the opinion that creative processes in composing have to a great extent the same cognitive structure, function, mechanisms and strategies as creative processes in other domains. The difference lies in the nature of the domains, materials, contents and skills. And on top of that are the qualities of the creative person, which make a major difference and greatly influence the idiosyncrasy of his/her creation. The existing research offers ideas about the next steps in developing the knowledge and understanding and material for the generation of future confluent models of composing. The secondary analysis of the results could be employed and used to integrate knowledge from different discourses, methodologies and disciplines. Besides that, the 'new age' should not forget the knowledge and wisdom of previous times. In addition, it seems that the interdisciplinary approach, supported by computer-based data collection, is necessary in order to gain more insight, knowledge and empirical results about the creative cognitive processes in composing music.

\section{Works cited}

Bahle, Julius: Der musikalische Schaffensprozeß: Psychologie der schöpferischen Erlebnis und Antriebsformen. Konstanz, Germany: Paul Christiani, 1947/1982.

Balaban, Mira, Kemel Ebcioglu, Otto E. Laske (Eds.): Understanding Music With AI: Perspectives on Music Cognition. Menlo Park, CA: The AAAI Press, 1992.

Berkowitz, Aaron L.: The Improvising Mind. Cognition and Creativity in the Musical Moment. New York: Oxford University Press, 2010, 8.

Bharucha, Jamshed J., Meagan E. Curtis, Paroo Kaivon: "Varieties of Musical Experience". Cognition, 100, 2006, 131-172. 
Bogunović, Blanka, Erić Milica: "Emocionalni doživljaj muzičkog komada: Komunikacija izmeću kompozitora, izvođača i publike" ["Emotional Experience of Musical Piece: Communication Between Composer, Performer and Audience”], in: Knjiga rezimea 22. konferencije Empirijska istraživanja u psihologiji [Abstract Book of 22. Conference on Empirical research in psychology]. Belgrade: Institute for Psychology and Laboratory for Experimental Psychology, Faculty of Philosophy, University of Belgrade, 2016, 43-44.

Bogunović, Blanka, Popović Mladjenović Tijana: "Emotion, Cognition and Imagery”, in: Tijana Popović Mladjenović, Blanka Bogunović, Ivana Perković: Interdisciplinary Approach to Music: Listening, Performing, Composing. Belgrade: Faculty of Music, 2014, 191-227.

Bogunović, Blanka: "Psihologija i muzika: Kognicija i afekat u stvaranju savremene umetničke muzike" ["Psychology and Music: Cognition and Affect in Creating Contemporary Art Music"], Paper presented at 24th International Review of Composers, Belgrade: Serbian composers' Association. Retrieved at $25^{\text {th }}$ January 2019 from http:// composers.rs/?page_id=4259

Brattico, Elvira, Mari Tervaniemi: "Musical creativity and the human brain", in: Irène Deliège, Geraint A. Wiggins (Eds.), Musical Creativity: Multidisciplinary Research in Theory and Practice. New York, NY: Psychology Press, 2006, 290-321.

Brown, Matthew: Debussy's Iberia. Oxford: Oxford University Press, 2003.

Byrne, Ruth M. J.: The Rational Imagination: How People Create Alternatives for Reality. Cambridge MA: MIT Press, 2005.

Collins, Dave: "A Synthesis Process Model of Creative Thinking in Music Composition", Psychology of Music, 33, 2005, 2, 193-216.

Collins, Dave: The Act of Musical Composition. Studies in the Creative Process. SEMPRE Studies in the Psychology of Music. New York: Routledge, 2016.

Csikszentmihalyi, Mihaly: "Implications of a Systems Perspective for the Study of Creativity”, in: Robert J. Sternberg (Ed.), Handbook of Creativity. Cambridge: Cambridge University Press, 2004, 313-335.

Deliège, Irène, Marc Richelle: "Prelude: The spectrum of Musical Creativity", in: Irène Deliège, Geraint A. Wiggins (Eds.), Musical Creativity: Multidisciplinary Research in Theory and Practice. New York, NY: Psychology Press, 2006, 1-6.

Donald, Merlin: "Art and Cognitive Evolution", in: Mark Turner (Ed.), The Artful Mind: Cognitive Science and the Riddle of Human Creativity. New York: Oxford University Press, 2006, 11-19.

Donin, Nicolas, Féron François-Xavier: "Tracking the Composer's Cognition in the Course of a Creative Process: Stefano Gervasoni and the Beginning of Gramigna”, Musicae Scientiae, 16, 2012, 3, 262.

Donin, Nicolas: "Empirical and Historical Musicologies of Compositional Processes: Towards a Cross-fertilization", in: Dave Collins (Ed.), The Act of Musical Composition: Studies in the Creative Process. Farnham, UK: Ashgate, 2012, 1-26.

Donin, Nikolas, Traube Caroline: "Tracking the Creative Process in Music: New Issues, New Methods”, Musicae Scientiae, 20, 2016, 3, 283-286. 
Emmerson, Simon: “Composing Strategies and Pedagogy”, Contemporary Music Review, 3, 1989, 133-144.

Finke, Ronald A., Ward Thomas B., Smith Steven M.: Creative Cognition: Theory, Research and Applications, Cambridge: MA, MIT Press, 1992.

Folkestad, Göran, David J. Hargreaves, Berner Lindström: "Compositional Strategies in Computer-based Music Making”, British Journal of Music Education, 15, 1997, 1, 83-98.

Galenson, David W.: Old Masters and Young Geniuses. Princeton, NJ: Princeton University Press, 2005.

Galenson, David W.: Painting Outside the Lines: Patterns of Creativity in Modern Art. Cambridge, MA: Harvard University Press, 2001.

Gruber, Howard E., Doris B. Wallace: “The Case Study Method and Evolving Systems Approach for Understanding Unique Creative People at Work", in: Robert J. Sternberg (Ed.), Handbook of Creativity. Cambridge: Cambridge University Press, 2004, 93-115.

Hacker, Douglas J.: “Definitions and Empirical Foundations”, in: Douglas. J. Hacker, John Dunlosky, Arthur C. Graesser (Eds.), Metacognition in Educational Theory and Practice. London: Lawrence Erlbaum Associates, 1999.

Hallam, Susan, Ian Cross, Michael Thaut: The Oxford Handbook of Music Psychology. New York: Oxford University Press, 2009.

Hallam, Susan: "The Development of Metacognition in Musicians: Implications for Education", British Journal of Education, 18, 2001, 1, 27-39.

Hayes, John R.: The Complete Problem Solver ( $2^{\text {nd }}$ edition). Hillsdale, NJ: Lawrence Erlbaum, 1989.

Impett Jonathan: "Making a Mark: The Psychology of Composition", in: Susan Hallam, Ian Cross, Michael Thaut (Eds.), The Oxford Handbook of Music Psychology. New York: Oxford University Press, 2009, 403-412.

Jorgensen, Harald, Susan Hallam: "Practicing", in: Susan Hallam, Ian Cross, Michael Thaut (Eds.), The Oxford Handbook of Music Psychology. New York: Oxford University Press, 2016, 449-465.

Kaufman, James C., Robert J. Sternberg: “Resource Review: Creativity”, Change, 39, 2007.

Kaufman, James C., Robert J. Sternberg: The Cambridge Handbook of Creativity. New York: Cambridge University Press, 2010.

Kaufman, James C., Robert J. Sternberg: The International Handbook of Creativity. New York: Cambridge University Press, 2006, 19.

Kostić, Aleksandar: Kognitivna psihologija [Cognitive Psychology]. Beograd: Zavod za udžbenike, 2010.

Kozbelt, Aaron, Ronald A. Beghetto, Mark A. Runco: “Theories of creativity”, in: James C. Kaufman, Robert J. Sternberg (Eds.), The Cambridge Handbook of Creativity. New York: Cambridge University Press, 2010, 20-47.

Kozbelt, Aaron: "Performance Time Productivity and Versatility Estimates for 102 Classical Composers", Psychology of Music, 37, 2009, 25-46. 
Kozbelt, Aaron: "A Quantitative Analysis of Beethoven as Self-critic: Implications for Psychological Theories of Musical Creativity", Psychology of Music, 35, 2007, 1, 144-168.

Kratus, John: "A Time Analysis of the Compositional Processes Used by Children Ages 7 to 11", Journal of Research in Music Education, 37, 1989, 1, 5-20.

Lehmann, Andreas C., Sloboda John A., Woody Robert H.: Psychology for Musicians. Understanding and Acquiring the Skills. New York: Oxford University Press, 2007, 133.

Leman, Marc: "Musical Creativity Research", in: James C. Kaufman, John Baer, Creativity Across Domains: Faces of the Muse. Boca Raton: Psychology Press, 2011, 103-122.

Lerdahl, Fred: "Cognitive constrains in compositional systems", in: John Sloboda (Ed.), Generative Processes in Music: The Psychology of Performance, Improvisation and Composition. Oxford, UK: Clarendon Press, 1988, 231-259.

Mandler, George: “Origins and Consequence of Novelty”, in: Steven M. Smith, Thomas B. Ward, Ronald A. Finke (Eds.), The Creative Cognition Approach. USA: MIT Press, 1997, 9-26.

McAdams, Stephen: "Problem-solving Strategies in Music Composition: A Case Study", Music Perception, 21, 2004, 3, 391-429.

McPherson, Gary, Barry J. Zimmerman: "Self-regulation of Musical Learning", in: Richard Colwell \& Carol Richardson (Eds.), The New Handbook of Research on Music Teaching and Learning. Oxford: Oxford University Press, 2002, 327-347.

North, Adrian C., David J. Hargreaves: The Social and Applied Psychology of Music. New York: Oxford University Press, 2008.

Ockelford, Adam: "Beyond Music Psychology", in: Susan Hallam, Ian Cross, Michael Thaut (Eds), The Oxford Handbook of Music Psychology. New York: Oxford University Press, 2009, 539-551.

Panić, Vladislav: Psihologija i umetnost [Psychology and Art]. Beograd: Zavod za udžbenike i nastavna sredstva, 1997.

Pearce, Marcus, Meredith David, Wiggins Geraint: "Motivations and Methodologies for Automation of the Compositional Process", Musiacae Scientiae, 6, 2002, 2, 119-147.

Pohjannoro, Ulla: “Capitalizing on Intuition and Reflection: Making Sense of a Composer's Creative Proces" Musicae Scientiae, 20, 2016, 2, 207-234.

Popović Mladjenović, Tijana, Blanka Bogunović, Ivana Perković: Interdisciplinary Approach to Music: Listening, Performing, Composing, Belgrade: Faculty of Music, 2014.

Popović Mladjenović, Tijana, Blanka Bogunović, Ivana Perković: "Nature versus Culture: Compositional Practices of Contemporary Serbian Composers", in: Tijana Popović Mlađenović, Blanka Bogunović, Ivana Perković, Interdisciplinary Approach to Music: Listening, Performing, Composing. Belgrade, Faculty of Music, 2014, 133188.

Radocy, Rudolf E., J. David Boyle: Psychological Foundation of Musical Behavior (4 $4^{\text {th }}$ edition). Springfield, Illinois: Charles C. Thomas, Publisher, 2003.

Radoš, Ksenija: Psihologija muzike [Psychology of Music]. Beograd: Zavod za udžbenike, 2010 ( $2^{\text {nd }}$ edition). 
Reynolds, Roger: "Compositional Strategies in the Angel of Death for Piano, Chamber Orchestra and Computer-processed Sound'”, Music Perception, 22, 2004, 2, 173 205.

Roels, Hans: "Comparing the Main Compositional Activities in a Study of Eight Composers”, Musicae Scientiae, 20, 2016, 3, 413-435.

Simonton, Dean K.: “Computer Content Analysis of Melodic Structure: Classical Composers and Their Compositions", Psychology of Music, 22, 1994, 31-34.

Simonton, Dean K.: "Creativity from Historiometric Perspective”, in: Robert J. Sternberg (Ed.), Handbook of Creativity. Cambridge: Cambridge University Press, 2004, 116133.

Simonton, Dean K.: "Emergence and Realization of Genius: The Lives and Works of 120 Classical Composers", Journal of Personality and Social Psychology, 61, 1991, 829840.

Simonton, Dean K.: "Emotion and Composition in Classical Music: Historiometric Perspectives", in: Patrik N. Juslin, John A. Sloboda (Eds.), Music and Emotion. Theory, Research, Applications. Oxford: Oxford University Press, 2010, 347-366.

Sloboda, John: Exploring the Musical Mind. Oxford: Oxford University Press, 2005.

Sloboda, John: The Musical Mind. Oxford: Oxford University Press, 1985.

Smith, Steven M., Thomas B. Ward, Ronald A. Finke: The Creative Cognition Approach. USA: MIT Press, 1997.

Stevens, Catherine, Tym Byron: “Universals in Musical Processing”, in: Susan Hallam, Ian Cross, Michael Thaut (Eds.), The Oxford Handbook of Music Psychology. New York: Oxford University Press, 2009, 14-23.

Wallas, Graham: The Art of Thought, New York: Harcourt, Brace, 1926.

Ward, Thomas B., Yuliya Kolomyts: "Cognition and Creativity", in: James C. Kaufman, Robert J. Sternberg (Eds.), The Cambridge Handbook of Creativity. New York: Cambridge University Press, 2010, 93-112.

Ward, Thomas B., Steven M. Smith, Ronald A. Finke: “Creative Cognition”, in: Robert J. Sternberg (Ed.), Handbook of Creativity. Cambridge: Cambridge University Press, 2004, 189-212.

Weisberg, Robert W.: "Creativity and Knowledge: A Challenge to Theories", in: Robert J. Sternberg (Ed.), Handbook of Creativity. Cambridge: Cambridge University Press, 2004, 226-250.

Willingham, Daniel T.: Cognition.New Jersey: Pearson Education International, 2007, 249-257.

Zbikowski, Lawrence M.: "Modelling the Groove: Conceptual Structure and Popular Music", Journal of the Royal Musical Association, 129, 2004, 2, 272-297.

Zbikowski, Lawrence M.: “The Cognitive Tango”, in: Mark Turner (Ed.), The Artful Mind: Cognitive Science and the Riddle of Human Creativity. New York: Oxford University Press, 2006, 115-132.

Zbikowski, Lawrence M.: Conceptualizing Music: Cognitive Structure, Theory, and Analysis. New York: Oxford University Press, 2002. 


\section{Summary}

In this paper we presented an overview of theoretical and empirical research in a domain of cognitive psychology of music, psychology of creativity and interdisciplinary studies concerning the creative cognitive processes in composing music, with an intention to bring them into connection and to raise questions about further research. We brought into focus the cognitive processes in composing music since the key role of cognitive mechanisms and processes, next to the emotional experience and imagery, was shown in our previous research. The wide scope of knowledge, within a time span of some 35 years, was introduced covering the following themes - generative models of creative cognition, metacognitive strategies in composing, the relation between creativity, knowledge and novelty, creativity in the social-economical context. We paid attention to the several crucial theoretical models, some of them developed on the basis of exploration of compositional practices, one of the first being John Sloboda's psychological Model of typical compositional recourses and processes (1985), that gave a global overview of the relevant components of the composing behavior. Psychology of creativity gave several process models that can be applied in a field of composing music. One of them, developed by Wallas (1926) and adapted for music making by Lehmann, Sloboda and Woody (2002), is the well-known theory of the creative process stages. We considered as the most prominent the Creative cognition approach formulated by Smith, Ward and Finke (1997) and their Geneplore model (1992). The authors listed a wide range of processes that are crucial for creativity, nevertheless they are engaged in the generative or exploratory phase. In our paper, we discussed metacognitive strategies engaged in a process of composing while considering music creation as a self-regulated activity. Further on, the relation between immersion, knowledge, the production of heuristic ideas and the cognitive strategies of problem solving were brought into focus. It was pointed out that quality of the creative outcomes will be influenced by the extent of the person's long-term knowledge structures, drawn intentionally or intuitively during the process, and by the manner in which the elements of that knowledge are accessed and combined. The social and cultural factors were considered in a frame of several confluent models, first of all Csikszentmihalyi's systems theory of creativity (2004), focused less on the creative person but on involving multiple factors. Simonton took into account massive and impersonal influences from the Zetgeist or Ortgeist and grouped them into four categories: cultural factors, societal factors, economic and political factors (2004). Further on, models and concepts, new research methodologies and new technology, that were developed specifically in a domain of music creation, as well as their results, were presented. 